\title{
Comparative effectiveness and safety of traditional Chinese medicine supporting Qi and enriching blood for cancer related anemia in patients not receiving chemoradiotherapy: a meta-analysis and systematic review
}

This article was published in the following Dove Press journal: Drug Design, Development and Therapy

\section{Zhibo Dang ${ }^{1,2, *}$ \\ Xiaoli Liu',* \\ Xinhui Wang' \\ Mengge Li ${ }^{1,2}$ \\ Yuyong Jiang' \\ Xianbo Wang' \\ Zhiyun Yang'}

'Center of Integrative Medicine, Beijing Ditan Hospital, Capital Medical University, Chaoyang District, Beijing I000I5, People's Republic of China;

${ }^{2}$ First Clinical Medical College, Beijing University of Chinese Medicine, Chaoyang District, Beijing 100029 , People's Republic of China

*These authors contributed equally to this work
Correspondence: Zhiyun Yang Center of Integrative Medicine, Beijing Ditan Hospital, Capital Medical University, No 8 Jingshun East Street, Chaoyang District, Beijing I000I5, People's Republic of China Tel/fax +86 I08432 2148 Email yangzhiyun020116@163.com

\begin{abstract}
A systematic review and meta-analysis of previous randomized controlled trials of traditional Chinese medicine (TCM) supporting Qi and enriching blood in the treatment of cancer related anemia (CRA) in patients not receiving chemoradiotherapy were conducted. A total of 13 randomized controlled trials were included. Compared with the control group, better improvement was found for the level of hemoglobin (mean difference $=4.57,95 \% \mathrm{CI}[1.38,7.76], P=0.005$ ) and overall therapeutic effect (risk ratio $[\mathrm{RR}]=1.31,95 \% \mathrm{CI}[1.18,1.46], P<0.000$ ) in the TCM groups. The incidence of related adverse events was not increased in the TCM groups ( $R R=0.54,95 \%$ CI $[0.29,0.99], P=0.05)$. However, due to the relatively low quality and the small sample sizes of the included studies, the results should be interpreted with a degree of caution. Nevertheless, TCM with the role of supporting Qi and enriching blood may be a safe and effective treatment for CRA in patients not receiving chemoradiotherapy and might be considered as an alternative treatment to conventional western medicine including iron supplements and erythropoietin.
\end{abstract}

Keywords: traditional Chinese medicine, supporting Qi and enriching blood, cancer related anemia, randomized controlled trial, meta-analysis

\section{Introduction}

As a common complication of tumors, the incidence of cancer related anemia (CRA) ranges from $30 \%$ to $90 \%,{ }^{1}$ which can be divided into nonchemotherapy- and chemotherapy-induced CRA. Without doubt, the lifestyle quality of these patients is decreased by this condition. ${ }^{2}$ Studies have shown that continuous anemia can cause tachycardia, palpitations, fatigue, respiratory disorders, and other symptoms. ${ }^{3}$ Therefore, the management of anemia in cancer patients is clinically important even though survival is the primary treatment goal. Current mainstream treatment methods include blood transfusions, iron supplements, and erythropoietin (EPO) therapy. However, these treatment methods have some disadvantages; blood transfusion is hampered by a relative shortage of blood donation and the potential survival risk to CRA patients due to transfusion-related complications such as anaphylaxis, iron overload, hemolysis, allogeneic immune response, thrombosis, posttransfusion cardiogenic pulmonary edema, and transfusion-induced viral infections. A careful inspection of a large patient database revealed that cancer patients who received red cell transfusions were more 
at risk of having venous thrombosis, arterial thrombosis, or of dying. ${ }^{4}$ Cancer patients who underwent surgery and who received red cell transfusions also had an increased mortality. ${ }^{5}$ Iron supplements are usually given for the management of iron deficiency anemia. ${ }^{6}$ However, hemochromatosis or cell injury can occur due to indiscriminate use of oral iron, ${ }^{7}$ and a poor medication compliance rate in these patients was reported, owing to the high frequency of gastrointestinal side effects. ${ }^{8}$ EPO is known to be very effective in improving the hematological response and reducing the need for blood transfusions. ${ }^{9}$

CRA has increasingly aroused general concern due to its high morbidity and potential influence on the quality of life of CRA patients, with an effective and safe therapeutic method for this condition being of obvious clinical significance. CRA is essentially a type of blood deficiency syndrome, and thus may be treated with traditional Chinese medicine (TCM). In fact, the knowledge and theoretical studies on blood deficiency in TCM are quite mature and have a profound theoretical and practical basis. Based on the relationship between Qi and blood and the relationship between Zangfu and blood generation, TCM formulas supporting Qi and enriching blood have been used to treat blood deficiency syndrome for a long time. In a recent meta-analysis, Zhu et al reported that Huangqi injection could significantly enhance the efficacy of androgens for aplastic anemia. ${ }^{10}$ Another study has also reported the therapeutic effect and safety profile of TCM formulas supporting Qi and enriching blood in the management of CRA, ${ }^{11}$ but the sample sizes in these studies were relative small. Thus we performed this meta-analysis to review systematically randomized controlled trials of TCM supporting Qi and enriching blood for the treatment of CRA in order to clarify in detail the effect and safety of TCM for its treatment.

\section{Materials and methods}

\section{Search strategy}

We performed an electronic search of PubMed, EMBASE, Cochrane, Chinese biological medicine, Chinese Scientific Journal Database, China Wanfang database, and China National Knowledge Infrastructure databases for previous studies on the therapeutic effects and safety of TCM for CRA, with no limitations on language or the publication year, using the following search keywords: "Traditional Chinese medicine supporting Qi and enriching blood" or "Chinese herbology supporting Qi and enriching blood" or "Chinese medicine supporting Qi and enriching blood" and "Cancer related anemia" or "malignant tumor anemia".
A Google Scholar search was also performed using these search terms.

\section{Eligibility criteria}

Randomized controlled trials that provided data on the therapeutic effect and safety of supporting Qi and enriching blood TCMs in patients with CRA compared to a control group who received conventional treatment were eligible for this metaanalysis. In addition, the involved subjects should be solid tumor patients with a hemoglobin level $<110 \mathrm{~g} / \mathrm{L}$. Studies in which patients received radiotherapy or chemotherapy during treatment or suffered with a disease that may affect the level of hemoglobin, such as aplastic anemia, were excluded.

\section{Data extraction}

Two reviewers (Zhibo Dang and Xiaoli Liu) independently extracted the following data from each study: first author's surname, publication year, country, the study design, number of patients in the control and TCM groups, male or female, the level of hemoglobin before and after the treatment, the overall therapeutic effect, and any adverse events.

\section{Outcome measurement indexes}

\section{Primary outcome indexes}

The level of hemoglobin was set as the primary outcome index.

\section{Secondary outcome indexes}

The overall therapeutic effect and adverse events were set as the secondary outcome indexes.

\section{Statistical analysis}

All statistical analyses were carried out using RevMan (ver 5.3). An OR was employed for the statistical analysis of the counting data and standardized mean difference or weighted mean difference (MD) were used to analyze statistically the measurement data. Statistical heterogeneity between studies was evaluated using a chi-squared test; $P>0.1$ and $\mathrm{I}^{2}<50 \%$ were taken to be of low heterogeneity, and a fixed effect model was used. $P<0.1$ and $\mathrm{I}^{2}>50 \%$ were considered to have statistical heterogeneity; therefore, a random effect model was employed. The heterogeneous source was analyzed and subgroup analysis carried out for factors that may lead to heterogeneity. If heterogeneity arose from low-quality research, sensitivity analysis was carried out. If there was still significant heterogeneity between the two groups, descriptive analysis was used. A $P$-value $<0.05$ was considered to be statistically significant, and all tests were two-sided. 


\section{Assessment of publications}

The methodology excellence of the included studies was evaluated following the guidelines laid down in the Cochrane Handbook for Systematic Reviews. The following factors were taken into account: allocation concealment; blinding of participants; personnel and outcome assessments; incomplete outcome data; random sequence generation; selective reporting; and other potential sources of bias.

\section{Results}

\section{Publication selection}

A total of 422 papers were obtained from the initial retrieval, of which 260 were excluded due to duplicate publication. A total of 96 papers were obtained after reviewing the title and summary according to the exclusion and inclusion criteria, and 13 were eventually included after a full-text review, which included a total of 1,198 patients (Figure 1). In these 13 studies, a different prescription was used in each study, but all of them were typical TCM formula used to improve the Qi and blood deficiency, which is termed anemia in western medicine. In the control group, EPO therapy was used in seven studies, iron supplements were used in three studies, and only antitumor and supportive therapies were used in two studies. One study used either EPO or iron supplements in the control group, but the authors did not clearly clarify which patients used EPO or iron supplement therapy. Eleven studies reported the results of hemoglobin levels and ten studies reported the results of the overall therapeutic effect. All these studies were conducted in Asian patients, one in Japan and the others in P.R. China (Table 1).

\section{Quality assessment of the selected publications}

The methodology quality of the included studies was relatively low. Five of the studies reported random methods, but all of these studies did not report allocation concealment, blinding of participants, personnel, or the outcome assessments. The outcome data in all of the studies were complete, and there was no selective reporting or bias (Figure 2).

\section{Hemoglobin}

A total of eleven studies ${ }^{11-21}$ reported changes in hemoglobin levels. A $P$-value $<0.001$ and $\mathrm{I}^{2}=97 \%$ indicated that there was

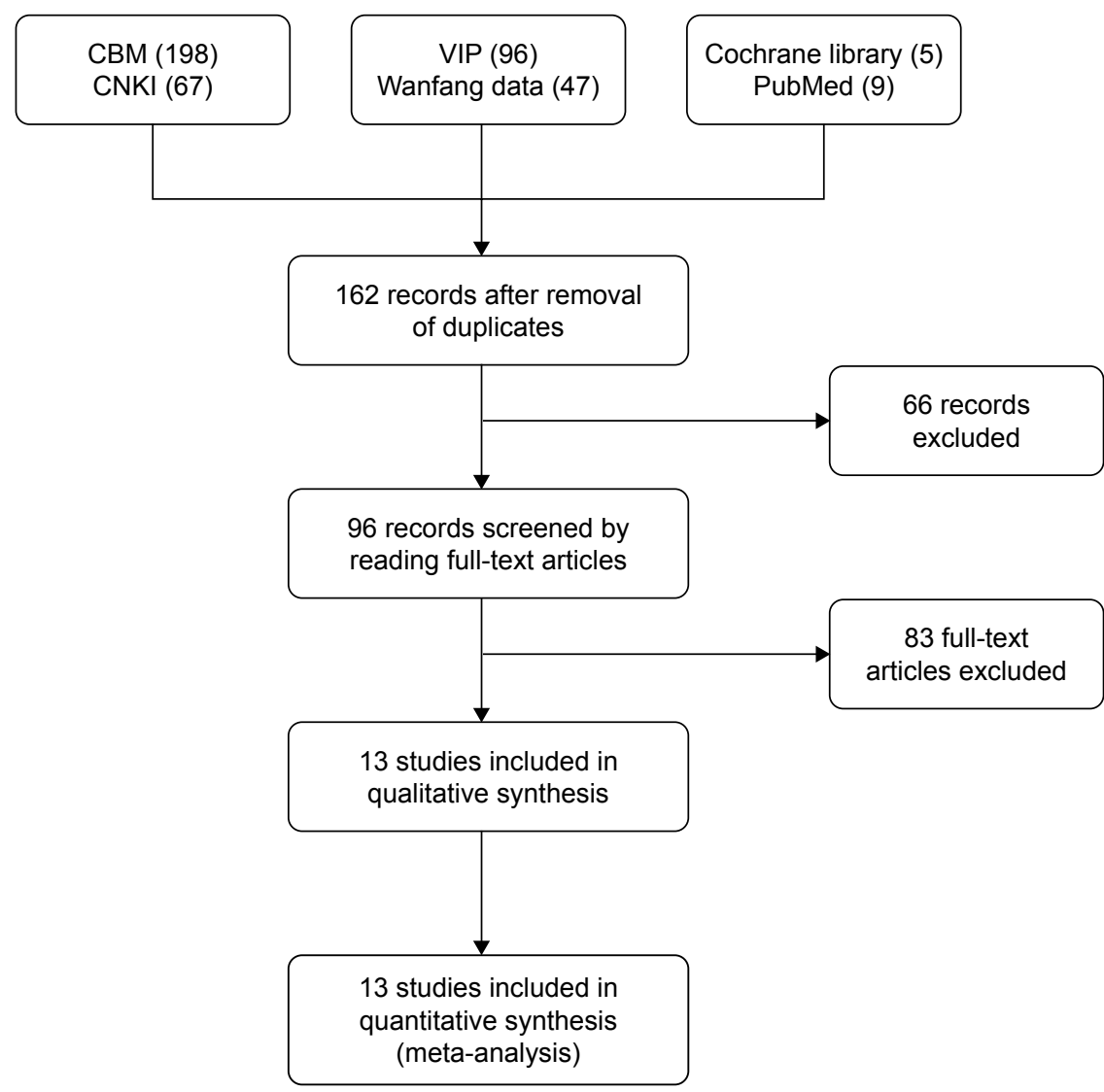

Figure I Characteristics of the randomized trials included in the meta-analysis and used search engines. Abbreviations: CBM, Chinese biological medicine; CNKI, China National Knowledge Infrastructure; VIP, China Science and Technology Journal Database. 
Table I The basic characteristics of the included literature

\begin{tabular}{|c|c|c|c|c|c|c|c|}
\hline \multirow[t]{2}{*}{ Subjects } & \multirow{2}{*}{$\begin{array}{l}\text { Publication } \\
\text { time }\end{array}$} & \multirow{2}{*}{$\begin{array}{l}\text { Number of } \\
\text { cases (human) } \\
\text { T/C }\end{array}$} & \multirow{2}{*}{$\begin{array}{l}\text { Gender } \\
\text { (male/ } \\
\text { female) }\end{array}$} & \multicolumn{2}{|l|}{ Intervention measures } & \multirow{2}{*}{$\begin{array}{l}\text { Outcome } \\
\text { measures }\end{array}$} & \multirow{2}{*}{$\begin{array}{l}\text { Course of } \\
\text { treatment }\end{array}$} \\
\hline & & & & Observation group & $\begin{array}{l}\text { Control } \\
\text { group }\end{array}$ & & \\
\hline Akase et al"I & 2003 & $10 / 15$ & Unreported & Danggui Shaoyao Powder & Chalybeate & (1)(3) & 8 weeks \\
\hline Cheng et al ${ }^{14}$ & 2009 & $33 / 32$ & $65 / 0$ & EPO & YXS + EPO & (1)(2) & 12 weeks \\
\hline Gu et a ${ }^{16}$ & 2010 & $63 / 50$ & $62 / 51$ & $\begin{array}{l}\text { Shenfu injection + conventional } \\
\text { therapy }\end{array}$ & $\begin{array}{l}\text { Conventional } \\
\text { therapy }\end{array}$ & (1) & 3 weeks \\
\hline Cai and Zhu'2 & 2016 & $45 / 44$ & $48 / 41$ & Modified Bazhen decoction & EPO & (1)(2)(3) & 8 weeks \\
\hline Cai and Wang ${ }^{13}$ & 2016 & $60 / 60$ & $64 / 56$ & YXS + conventional therapy & $\begin{array}{l}\text { Conventional } \\
\text { therapy }\end{array}$ & (1)(2) & 30 days \\
\hline Du et al ${ }^{15}$ & 2015 & $43 / 43$ & $45 / 4 I$ & $\begin{array}{l}\text { Tonifying blood and nourishing Qi } \\
\text { decoction + conventional therapy }\end{array}$ & $\begin{array}{l}\text { Conventional } \\
\text { therapy }\end{array}$ & (1) & 3 months \\
\hline Ling et $\mathrm{al}^{17}$ & 2016 & $50 / 50$ & $71 / 29$ & $\begin{array}{l}\text { Self-made Chinese herbal } \\
\text { decoction }+ \text { conventional therapy }\end{array}$ & $\begin{array}{l}\text { Conventional } \\
\text { therapy }\end{array}$ & (1)(2) & 4 weeks \\
\hline Liu and $\mathrm{Liao}^{22}$ & 2015 & $44 / 44$ & $40 / 48$ & Shen Bai Fu Zheng granule + EPO & EPO & (1)(3) & 8 weeks \\
\hline $\operatorname{Liu}^{18}$ & 2015 & $46 / 46$ & $60 / 32$ & $\begin{array}{l}\text { Self-made warming kidney and } \\
\text { invigorating spleen and enriching } \\
\text { blood decoction }\end{array}$ & $\begin{array}{l}\text { Folic acid } \\
\text { and ferrous } \\
\text { succinate }\end{array}$ & (1)(2) & 30 days \\
\hline Lv et $\mathrm{al}^{19}$ & 2016 & $56 / 56$ & Unreported & Self-made decoction + EPO & EPO & (1)(2) & 4 weeks \\
\hline Wang and $\mathrm{Li}^{20}$ & 2015 & $40 / 40$ & $43 / 37$ & $\begin{array}{l}\text { Tonifying kidney strengthening } \\
\text { spleen and enriching blood } \\
\text { decoction + conventional therapy }\end{array}$ & $\begin{array}{l}\text { Conventional } \\
\text { therapy }\end{array}$ & (1)(2) & 30 days \\
\hline Zhang ${ }^{23}$ & 2007 & $50 / 50$ & $52 / 48$ & Self-made decoction + EPO & EPO & (1) & 4 weeks \\
\hline $\mathrm{Zi}^{21}$ & 2016 & $64 / 64$ & $73 / 55$ & Shengxue tiaoyuan granule + EPO & EPO & (1)(2)(3) & 6 weeks \\
\hline
\end{tabular}

Notes: (1) hemoglobin; (2) curative effects; (3) untoward effects.

Abbreviations: EPO, erythropoietin; YXS, Yixuesheng capsule; T/C, treatment/control group.

significant heterogeneity among the studies; thus a random effect model was employed. In the pooled results, the level of hemoglobin in the TCM group was greater than that in the control group $(\mathrm{MD}=4.57,95 \% \mathrm{CI}[1.38,7.76], P=0.005$; $\mathrm{I}^{2}=97 \%$ ) (Figure 3).

\section{Subgroup analysis according to the therapeutic period and therapy method in the control group}

In order to analyze further the source of significant heterogeneity, subgroup analysis by the follow-up period and therapy method in the control group were separately performed.

First, subgroup analysis was performed according to the different therapeutic period. In the eleven studies, which reported changes in hemoglobin levels, the therapeutic period ranged from 3 weeks to 3 months and was divided into three subgroups: $\leq 30$ days for subgroup $1 ; 31$ days to 2 months for subgroup 2; and $>2$ months for subgroup 3 . However, significant heterogeneity was still found in these subgroups; the level of hemoglobin in the TCM group was significantly greater than that in the control group for subgroup 1 ( $\mathrm{MD}=8.72,95 \% \mathrm{CI}[4.62,12.83], P<0.000$; $\left.\mathrm{I}^{2}=97 \%\right)$ and subgroup $3(\mathrm{MD}=2.92,95 \%$ CI $[1.61,4.22]$,
$P<0.000 ; \mathrm{I}^{2}=0 \%$ ), but was significantly lower for subgroup $2\left(\mathrm{MD}=-3.77,95 \% \mathrm{CI}[-17.75,10.21], P=0.60 ; \mathrm{I}^{2}=97 \%\right.$ ) (Figure 4A).

Second, subgroup analysis was performed according to the therapy method in the control group. In the eleven studies that reported changes in hemoglobin levels, EPO therapy was employed as the control in six studies, and iron supplements were used in three studies; thus we divided them into EPO and iron supplements subgroups. In a further subgroup analysis, we found that the levels of hemoglobin in the TCM group was significantly higher than that in the control group for both subgroups (EPO subgroup: $\mathrm{MD}=3.85$, 95\% CI [2.18, 5.52], $P<0.000 ; \mathrm{I}^{2}=86 \%$; iron supplements subgroup: $\mathrm{MD}=6.68,95 \% \mathrm{CI}[-14.49,27.85], P=0.54$; $\mathrm{I}^{2}=99 \%$ ) (Figure 4B).

\section{Sensitivity analysis}

We found that the pooled results for comparison of hemoglobin levels between the two groups did not show obvious changes after excluding studies that reported hemoglobin levels one by one, and all of these results achieved statistical significance, thus indicating that the pooled results data had good stability. 


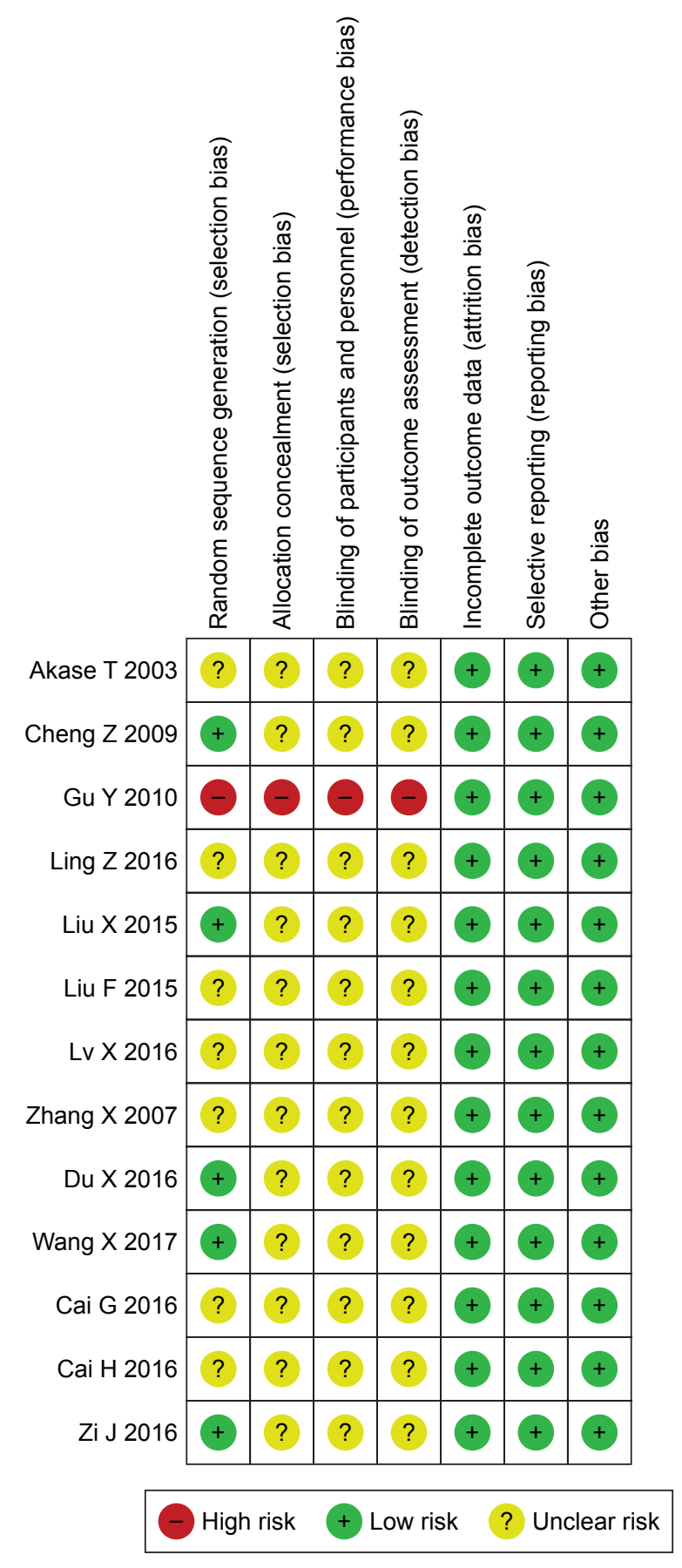

Figure 2 Risk of bias summary and methodology quality of the enrolled RCT publications studies.

Notes: red circle, high risk; green circle, low risk; yellow circle, unclear risk.

Abbreviation: RCT, randomized controlled trial.

\section{The overall therapeutic effect and adverse events}

A total of ten studies ${ }^{12-14,17-23}$ reported the results of the overall therapeutic effects. In these studies, the therapeutic effects were summarized as "obvious effect", "moderate effect", "mild effect", and "no efficacy" according to symptoms such as dizziness and facial pallor. However, the former three were classified as "effective" in this review in order to reduce the bias due to no standard criteria for the subjective therapeutic effect. A result of $P=0.03$ and $\mathrm{I}^{2}=51 \%$ indicated significant heterogeneity; thus, a random effect model was employed. For the pooled results, a significant improvement in the overall therapeutic effect was found in the TCM group compared to the control group (risk ratio $[\mathrm{RR}]=1.31,95 \% \mathrm{CI}$ $[1.18,1.46], P<0.000 ; I^{2}=51 \%$ ) (Figure 5A).

A subgroup analysis was also performed according to EPO or iron supplement therapy in the control group, and we found the overall therapeutic effect was significantly better in the TCM group than in the control group for both subgroups (EPO subgroup: RR=1.43, 95\% CI [1.30, 1.58], $P<0.000 ; \mathrm{I}^{2}=27 \%$; iron supplement subgroup: $\mathrm{RR}=1.30,95 \%$ CI $[1.09,1.56], P=0.004 ; \mathrm{I}^{2}=0 \%$ ), and the heterogeneity was obviously decreased (Figure 5B).

A total of four studies reported the results of adverse events, with a result of $P=0.14$ and $\mathrm{I}^{2}=45 \%$ indicating low heterogeneity, and a fixed effect model was employed. In the pooled results, the incidence of adverse events was significantly reduced in the TCM group compared to that in the control group $(\mathrm{RR}=0.54,95 \% \mathrm{CI}[0.29,0.99], P=0.05$; $\mathrm{I}^{2}=45 \%$ ) (Figure $5 \mathrm{C}$ ).

\section{Discussion}

As a disease caused by the tumor itself or the treatment, CRA has been reported to be improved or cured by TCM by supporting Qi and enriching the blood. In this meta-analysis, we systematically reviewed studies on the therapeutic effect and safety of TCM formulas for the treatment of CRA in patients not receiving chemoradiotherapy, and a significant improvement in the hemoglobin level was found after TCM treatment compared with that in the control group ( $\mathrm{MD}=4.57,95 \%$ CI $\left.[1.38,7.76], P=0.005 ; \mathrm{I}^{2}=97 \%\right)$. Promising results were also found for the overall therapeutic effect $(\mathrm{RR}=1.31,95 \%$ CI $\left.[1.18,1.46], P<0.000 ; I^{2}=51 \%\right)$. This finding was expected because the evaluation parameters for the overall therapeutic effect in these studies, including symptoms such as facial pallor and dizziness, would theoretically be improved after an increase in hemoglobin levels. However, the significant improvement in hemoglobin levels and the overall therapeutic effect in the TCM group should be cautiously interpreted due to substantial heterogeneity. Therefore, subgroup analysis was performed to explore the source of the heterogeneity, but an opposite changing trend of heterogeneity was found, that had significantly higher heterogeneity in the therapeutic period or in the control method subgroups for hemoglobin levels and obviously decreased heterogeneity for the overall therapeutic 


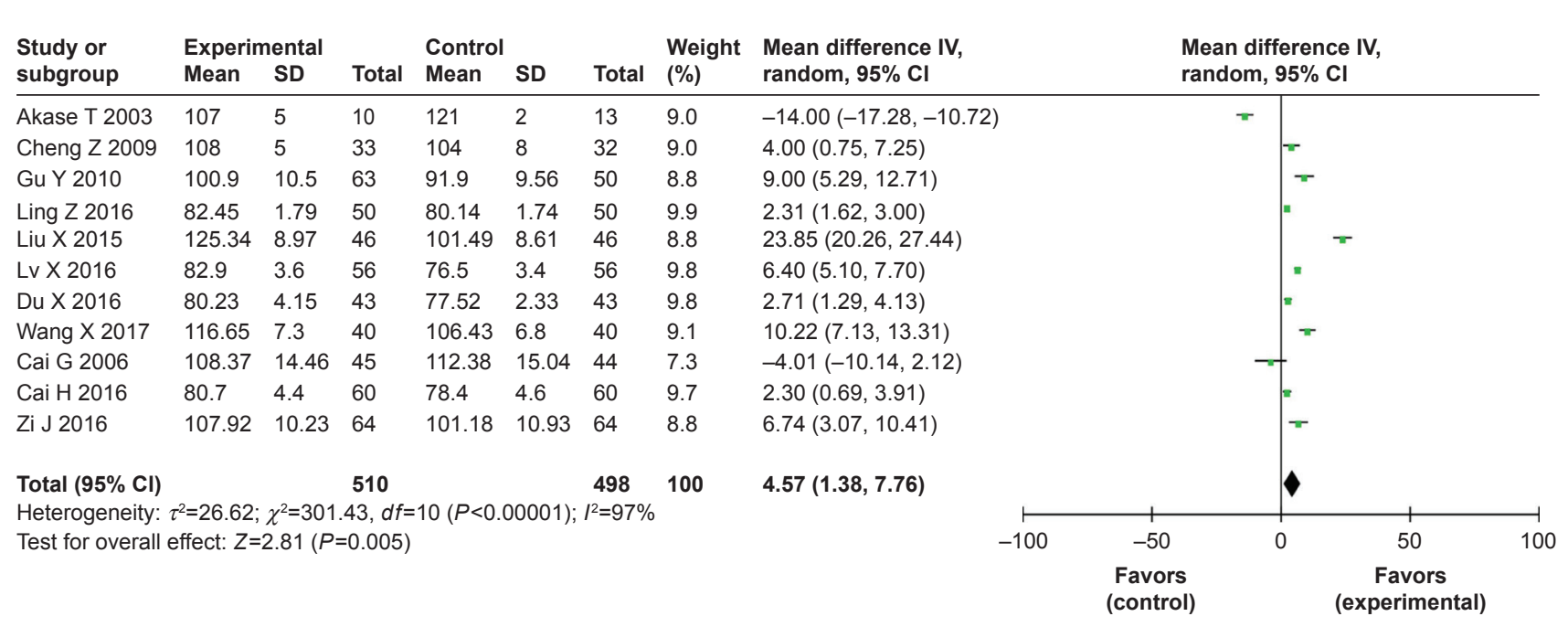

Figure 3 Forest plots of hemoglobin level changes in the enrolled RCT studies, and $P=97 \%$ indicated a significant heterogeneity among the studies $(P<0.00 \mathrm{I})$. Abbreviation: RCT, randomized controlled trial.

effect. Thus, some other factors, such as race or regions, may be responsible for this significant heterogeneity, and further subgroup analysis could not be carried out due to the few number of studies in Caucasians or western countries.

These significant improvements may be attributed to TCM's antitumor actions and the promotion of hemoglobin formation. The effective components of TCM such as astragalus polysaccharide and ginseng polysaccharide can suppress tumor growth through a variety of mechanisms such as regulating the immune function of the body, inhibition of tumor angiogenesis, induction of tumor cell apoptosis, and induction of differentiation of tumor cells. ${ }^{24}$ For example, Chinese medicine polysaccharide can activate $\mathrm{T}$ and $\mathrm{B}$ lymphocytes, macrophages, natural killer cells, cytotoxic $\mathrm{T}$ cells, dendritic cells, and other immune cells and can stimulate the production of a variety of cytokines including IL1, IL2, IL6, interferon, and tumor necrosis factor that enhance the body's immune function..$^{25}$ On the other hand, Chinese hematinic medicine is sweet, warm, and nurturing. The commonly used hematinic medicines such as Angelica, Radix paeonia alba, Radix rehmanniae preparata, and donkey-hide gelatin have been reported to promote the production of red blood cells and hemoglobin. ${ }^{26}$ In the published studies, the Chinese medicine used in the TCM group included traditional prescription, Chinese patent medicine, and self-prescription medicine, which covered all types of TCM used for the treatment of CRA. The most commonly used Chinese medicines in the studies were Codonopsis pilosula, Astragalus, and Angelica. In animal experiments, subcutaneous injection of Codonopsis pilosula decoction obviously increased the number of rabbit red blood cells and hemoglobin levels. ${ }^{27}$ Astragalus polysaccharide has an immunomodulatory effect, which can effectively enhance the activity of NK cells, promoting the transformation of $T$ lymphocytes and thus playing an anticancer role. It has been proven that the combination of Astragalus polysaccharide with chemotherapy drugs improves the quality of life and survival time of patients with progressive non-small cell lung cancer. ${ }^{28}$ Angelica is a major Chinese hematinic medicine, which can repair the hematopoietic function by stimulating the cells and molecules associated with hematopoiesis. ${ }^{29}$ Therefore, a rational combination of these Chinese medicines could theoretically enhance the antitumor effect and improve blood deficiency, and eventually show a significant therapeutic effect on CRA. In the present study, this assertion was proven by the obvious improvement in hemoglobin levels and the overall therapeutic effect in the TCM group compared to that in the control group.

A significant reduction in the incidence of adverse events was also found in the TCM group compared to that in the control group. A total of 14 cases of adverse events were found in this study, including 3 cases of skin rashes or incidence of hypertension; 2 cases of anorexia, allergies or nausea; and 1 case of liver dysfunction or fatigue. All of these adverse events occurred in studies that employed TCM compounds, which is consistent with the findings that the occurrence of adverse events rose with an increase in the TCM composition. ${ }^{30}$ It is worth mentioning that most of the TCM were orally administered, and the incidence of adverse events may be increased by intravenous injection administration; thus, this may be one of the reasons for reduced adverse events in the TCM group.

This study has some limitations. First, our results may have some inherent bias due to an unclear random method, allocation concealment, and blinding in these studies. Second, the sample 


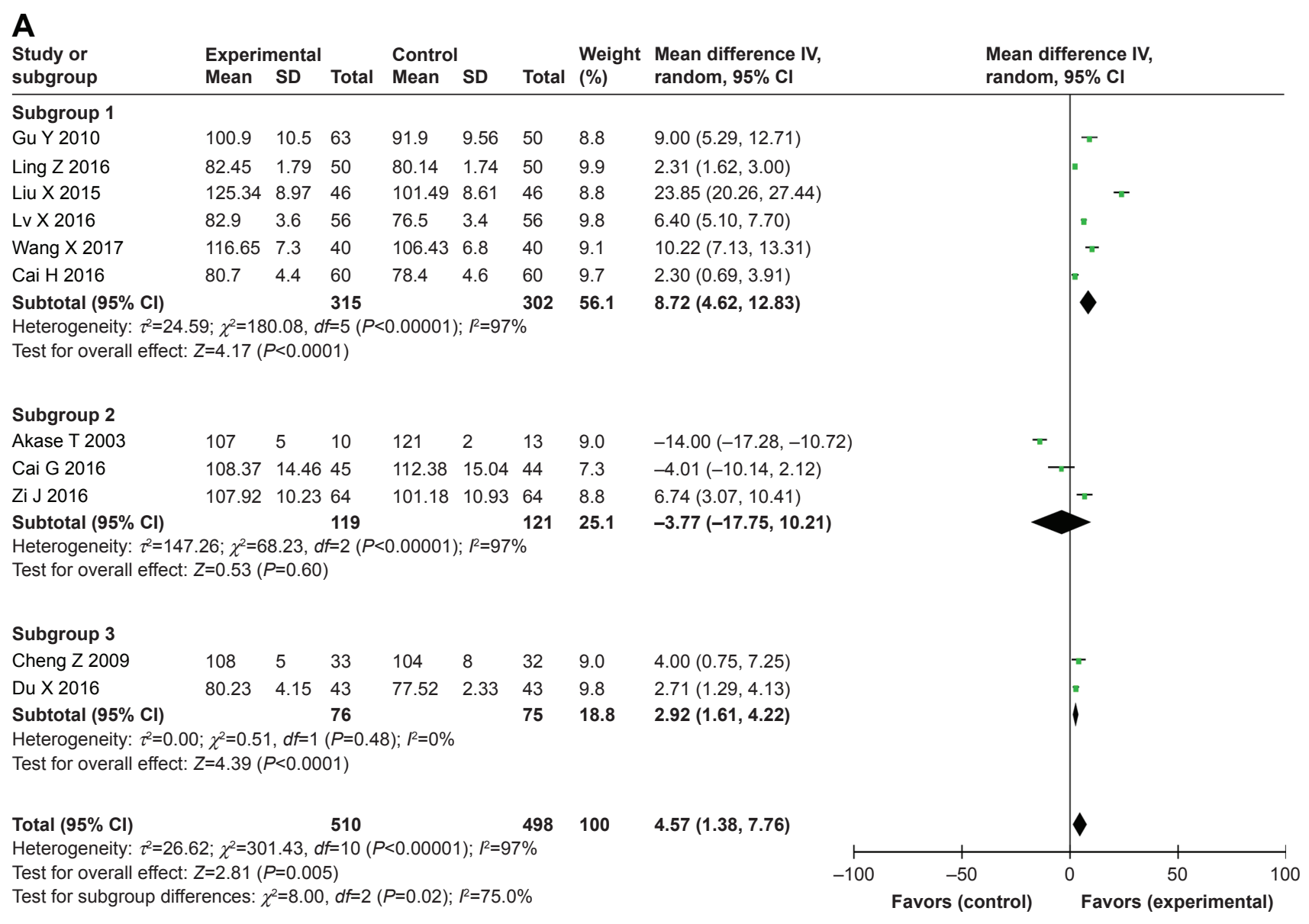

B

\begin{tabular}{|c|c|c|c|c|c|c|c|c|}
\hline $\begin{array}{l}\text { Study or } \\
\text { subgroup }\end{array}$ & $\begin{array}{l}\text { Experir } \\
\text { Mean }\end{array}$ & $\begin{array}{l}\text { nental } \\
\text { SD }\end{array}$ & Total & $\begin{array}{l}\text { Contro } \\
\text { Mean }\end{array}$ & SD & Total & $\begin{array}{l}\text { Weight } \\
(\%)\end{array}$ & $\begin{array}{l}\text { Mean difference } \\
\text { random, } 95 \% \mathrm{Cl}\end{array}$ \\
\hline \multicolumn{9}{|l|}{ EPO group } \\
\hline Cheng Z, Wu JL 2009 & 108 & 5 & 33 & 104 & 8 & 32 & 10.7 & $4.00(0.75,7.25)$ \\
\hline Ling Z 2016 & 82.45 & 1.79 & 50 & 80.14 & 1.74 & 50 & 11.8 & $2.31(1.62,3.00)$ \\
\hline Lv X 2016 & 82.9 & 3.6 & 56 & 76.5 & 3.4 & 56 & 11.7 & $6.40(5.10,7.70)$ \\
\hline Du X 2016 & 80.23 & 4.15 & 43 & 77.52 & 2.33 & 43 & 11.6 & $2.71(1.29,4.13)$ \\
\hline Cai H 2016 & 80.7 & 4.4 & 60 & 78.4 & 4.6 & 60 & 11.6 & $2.30(0.69,3.91)$ \\
\hline Zi J 2016 & 107.92 & 10.23 & 64 & 101.18 & 10.93 & 64 & 10.5 & $6.74(3.07,10.41)$ \\
\hline Subtotal $(95 \% \mathrm{Cl})$ & & & 306 & & & 305 & 67.9 & $3.85(2.18,5.52)$ \\
\hline
\end{tabular}

Heterogeneity: $\tau^{2}=3.33 ; \chi^{2}=35.16, d f=5(P<0.00001) ; l^{2}=86 \%$

Test for overall effect: $Z=4.51(P<0.00001)$

Iron supplement

Liu X 2015

Wang $X 2017$

$\begin{array}{lll}107 & 5 & 10 \\ 125.34 & 8.97 & 46 \\ 116.65 & 7.3 & 40\end{array}$

$\begin{array}{lll}121 & 2 & 13\end{array}$

$10.7-14.00(-17.28,-10.72)$

$\begin{array}{lllll}101.49 & 8.61 & 46 & 10.5 & 23.85 \\ (20.26,27.44)\end{array}$

Subtotal $(95 \% \mathrm{Cl})$

$\begin{array}{llll}106.43 & 6.8 & 40 & 10.8\end{array}$

$10.22(7.13,13.31)$

Heterogeneity: $\tau^{2}=347.03 ; \chi^{2}=244.42, d f=2(P<0.00001) ; l^{2}=99 \%$

Test for overall effect: $Z=0.62(P=0.54)$

Total $(95 \% \mathrm{Cl})$

402

$404 \quad 100$

$4.86(1.37,8.34)$

Heterogeneity: $\tau^{2}=26.69 ; \chi^{2}=286.99, d f=8(P<0.00001) ; l^{2}=97 \%$

Test for overall effect: $Z=2.73(P=0.006)$

Test for subgroup differences: $\chi^{2}=0.07, d f=1(P=0.79) ; I^{2}=0 \%$

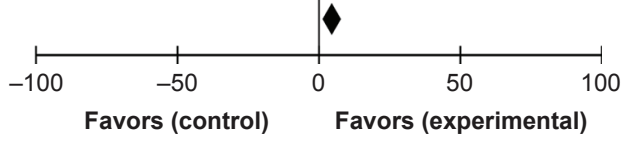

Figure 4 Subgroup analysis was performed with the follow-up period and therapy method in the control group for finding the source of significant heterogeneity.

Notes: (A) Analysis of changes in hemoglobin levels in the follow-up period subgroups I ( $\leq 30$ days), 2 ( 3 I days to 2 months), and 3 ( $>2$ months). (B) Analysis of changes in hemoglobin levels between I) TCM vs EPO and 2) TCM vs iron supplement subgroups.

Abbreviations: EPO, erythropoietin; TCM, traditional Chinese medicine. 
A

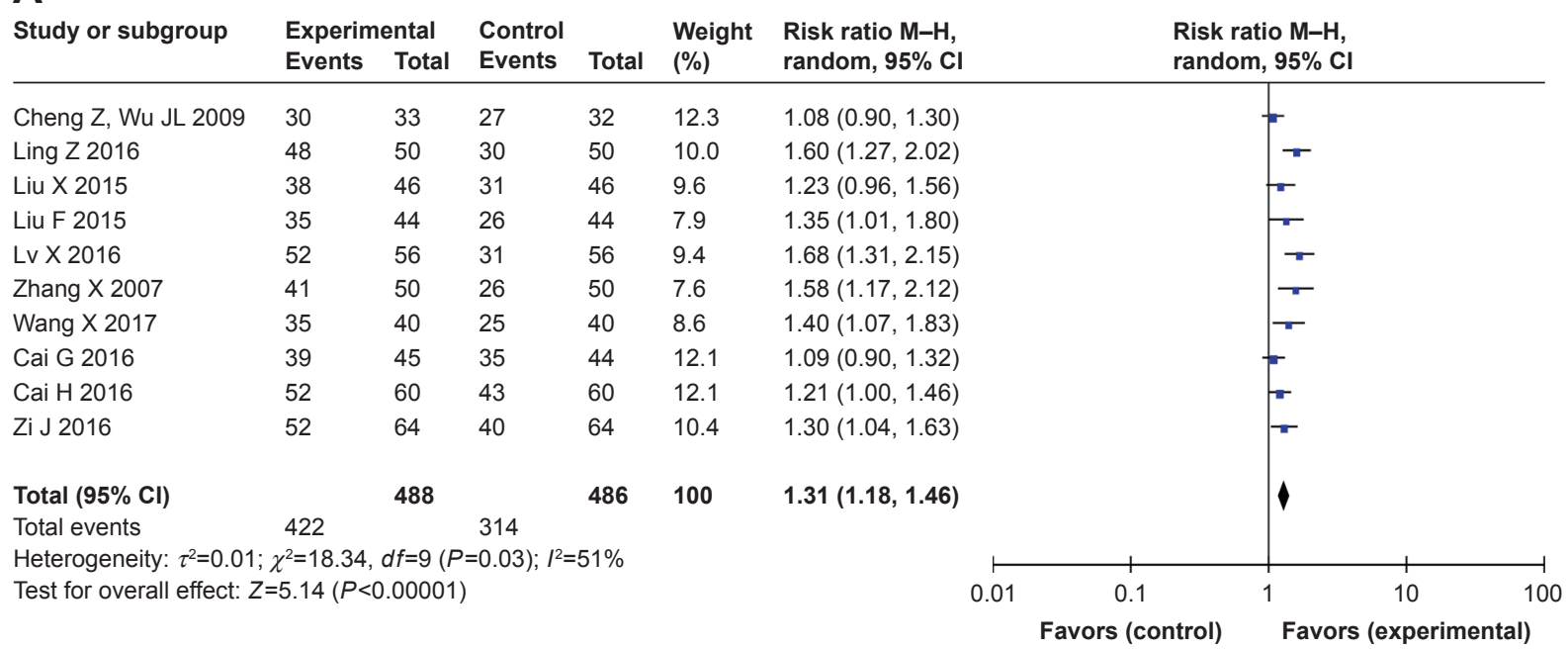

B

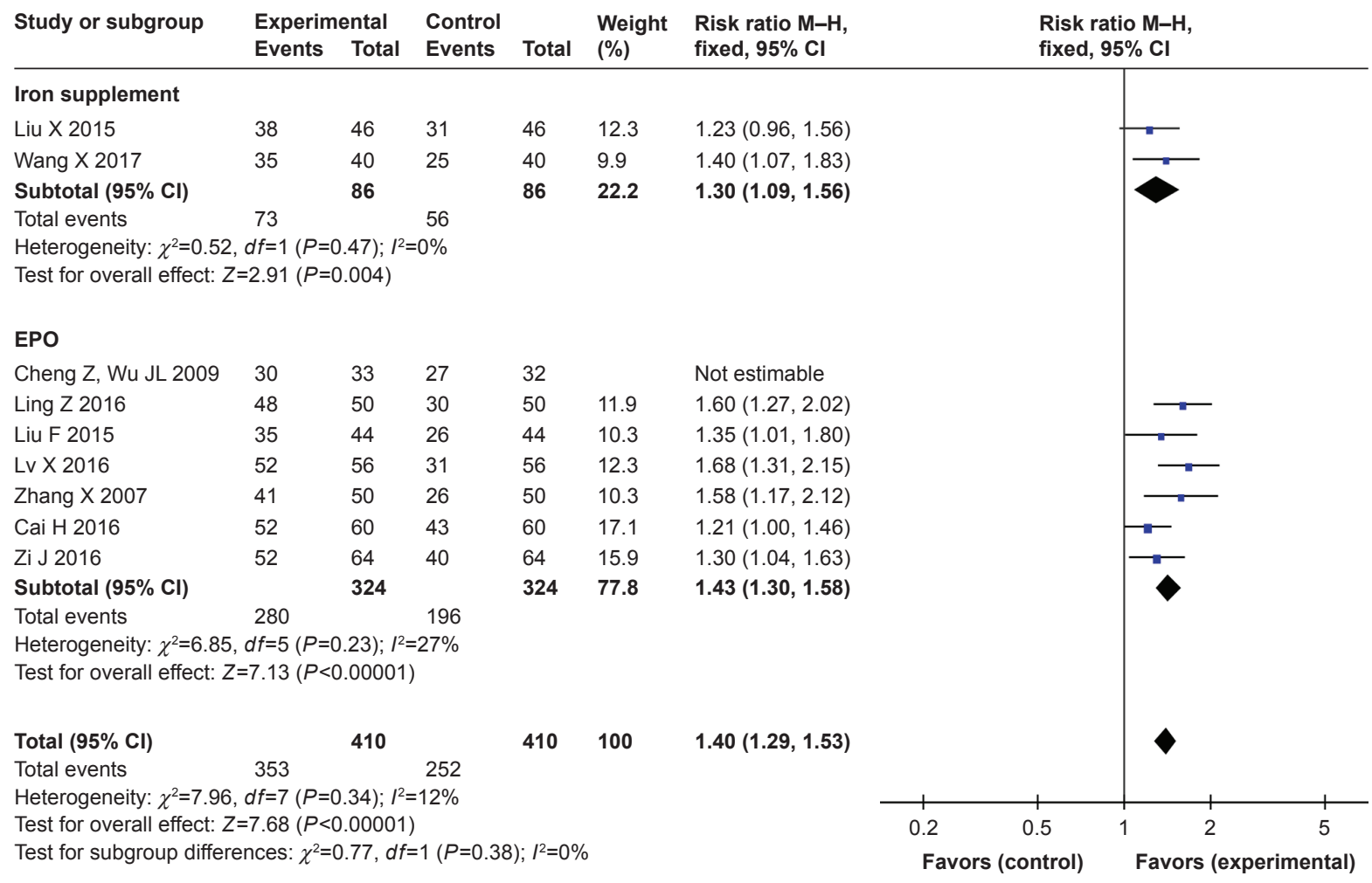

C

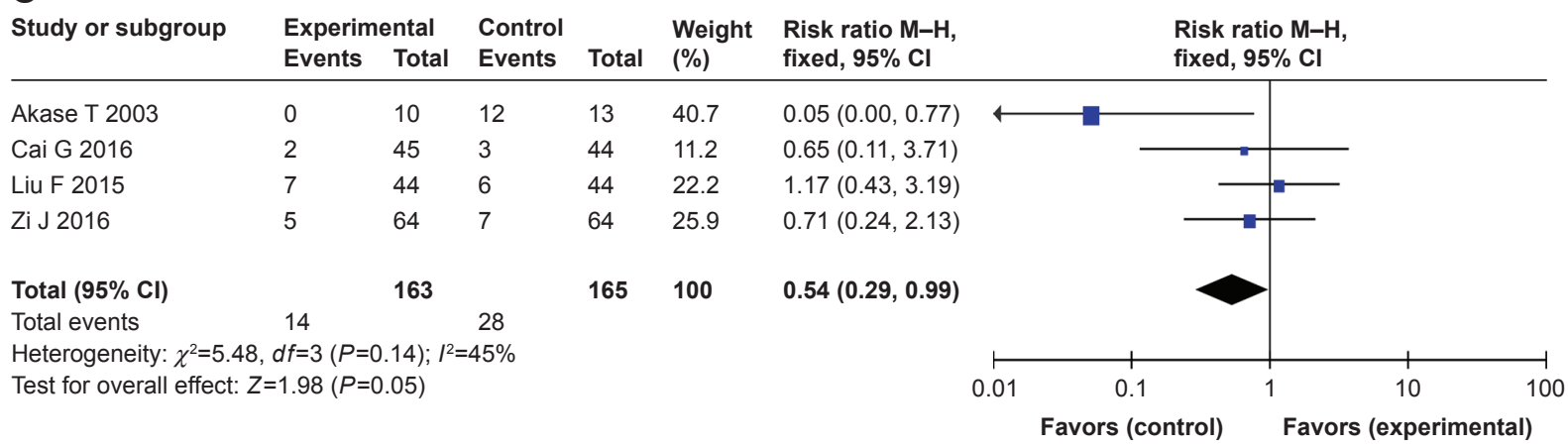

Figure 5 Analysis of the overall therapeutic effects in this meta-analysis (A) in 10 included studies; (B) in iron supplement and EPO control studies; (C) analysis of adverse events in the pooled results.

Abbreviation: EPO, erythropoietin. 
size of these studies was relatively small, and all of them were limited to Asian populations and regions. A further subgroup analysis was not possible and the pooled results may not be acceptable for other populations in other world regions. Third, there is a lack of uniform efficacy evaluation criteria; hence, the pooled results may have some bias owing to roughly dividing the subjective therapeutic effect into "effective" and "not effective". Finally, since the meta-analysis excluded all reports on patients under chemotherapy or radiotherapy, treatment-related anemia remained outside the scope of our study.

\section{Conclusion}

An analysis of current data shows that TCM formulas supporting Qi and enriching blood may be a safe and effective treatment of CRA in patients not receiving chemoradiotherapy and could be considered as an alternative treatment to conventional therapy. There is a certain clinical significance when the risk and cost of blood transfusions, iron supplements, and EPO injections are considered. However, due to the relatively low quality and the small sample sizes of the included studies, the results should be interpreted cautiously. A well-designed, multicenter, and large-sample study is needed to confirm the therapeutic effect and safety of TCM formulas in supporting Qi and enriching the blood for the treatment of CRA in patients not receiving chemoradiotherapy.

\section{Acknowledgment}

The study was supported by the Fund of Special Research of TCM in Capital City (No 17ZY02), Application of Clinical Features of Capital City of Science and Technology Commission (No Z171100001017082), and the Fund of Beijing Science \& Technology Development of TCM (No JJ2016-14).

\section{Author contributions}

ZY was responsible for the conception and design of the study. All authors contributed to data analysis, drafting and revising the article, gave final approval of the version to be published, and agree to be accountable for all aspects of the work.

\section{Disclosure}

The authors report no conflicts of interest in this work.

\section{References}

1. Knight K, Wade S, Balducci L. Prevalence and outcomes of anemia in cancer: a systematic review of the literature. Am J Med. 2004; 7A(116 Suppl):11S-26S.

2. Wasada I, Eguchi H, Kurita M, et al. Anemia affects the quality of life of Japanese cancer patients. Tokai J Exp Clin Med. 2013;38(1):7-11.
3. Ludwig H, van Belle S, Barrett-Lee P, et al. The European Cancer Anaemia Survey (ECAS): a large, multinational, prospective survey defining the prevalence, incidence, and treatment of anaemia in cancer patients. Eur J Cancer. 2004;40(15):2293-2306.

4. Khorana AA, Francis CW, Blumberg N, Culakova E, Refaai MA, Lyman GH. Blood transfusions, thrombosis, and mortality in hospitalized patients with cancer. Arch Intern Med. 2008;168(21):2377-2381.

5. Schrijvers D. Management of anemia in cancer patients: transfusions. Oncologist. 2011;16(Suppl 3):12-18.

6. Quintana-DíazM, Fabra-Cadenas S, Gómez-RamírezS, Martínez-Virto A, García-Erce JA, Muñoz M. A fast-track anaemia clinic in the emergency department: feasibility and efficacy of intravenous iron administration for treating sub-acute iron deficiency anaemia. Blood Transfus. 2016; 14(2):126-133.

7. Kato J, Kobune M, Kohgo Y, et al. Hepatic iron deprivation prevents spontaneous development of fulminant hepatitis and liver cancer in Long-Evans Cinnamon rats. J Clin Invest. 1996;98(4):923-929.

8. Powers JM, Buchanan GR, Adix L, Zhang S, Gao A, Mccavit TL. Effect of low-dose ferrous sulfate vs iron polysaccharide complex on hemoglobin concentration in young children with nutritional iron-deficiency anemia: a randomized clinical trial. JAMA. 2017;317(22):2297-2304.

9. Zhao F, Wang Y,LiuL, Bian M. Erythropoietin for cancer-associated malignant anemia: a meta-analysis. Mol Clin Oncol. 2017;6(6):925-930.

10. Zhu C, Gao Y, Jiang T, Hao C, Gao Z, Sun Y. Meta-analysis of Huangqi injection for the adjunctive therapy of aplastic anemia. Int J Clin Exp Med. 2015;8(7):10256-10264.

11. Akase T, Akase T, Onodera S, et al. A comparative study of the usefulness of toki-shakuyaku-san and an oral iron preparation in the treatment of hypochromic anemia in cases of uterine myoma. Yakugaku Zasshi. 2003;123(9):817-824.

12. Cai G, Zhu J. Clinical effect of modified Bazhen decoction in the treatment of mild and moderate cancer related anaemia. Chin West Med Zhejiang Province. 2016;26(7):637-639.

13. Cai H, Wang M. The effect of combined Chinese and western medicine on platelet count, hemoglobin and serum ferritin in patients with neoplastic anemia. Clin Rational Drug Use. 2016;9(11):55-56.

14. Cheng Z, Wu JL, Chen JF. Clinical observation on the treatment of male neoplastic anemia with Yixuesheng capsule combined with recombination human erythropoietin. Chin J Integr Med. 2009;15(1):63-65.

15. Du X, Xiang Y, Cheng Y, Meng X. The feasibility of the combination of Chinese and western medicine in the treatment of oncology anemia. Med Equip. 2016;29(8):147-148.

16. Gu Y, Xu H, Zhao M. Clinical study on effect of Shenfu injection treating cancer-related fatigue of patients with advanced carcinoma. Zhongguo Zhong Yao Za Zhi. 2010;35(7):915-918.

17. Ling Z, Wu J, Zhu Y. Clinical efficacy of Chinese and western medicine in the treatment of neoplastic anemia. Chin Foreign Med Treat. 2016; 35(31):166-168.

18. Liu X. Clinical efficacy of Jianpiwenshen therapy in the treatment of cancer related anemia. Chin Prescription Drugs. 2015;13(11):95-96.

19. Lv X, Kong Q, Yuan C, Liu L, Yu T. Clinical efficacy of Chinese and western medicine in the treatment of neoplastic anemia. Prevent Control Endem Dis China. 2016;31(9):1078.

20. Wang X, Li K. Clinical observation on Bushen Jianpi Shengxue formula in treatment of cancer-related anemia. J Liaoning Tradit Chin Med Univ. 2015;17(2):164-167.

21. Zi J. Comparative study between recombinant human erythropoietin combined blood production particles and single recombinant human erythropoietin in the treatment of cancer-related anemia. Modern Tradit Chin West Med. 2016;25(33):3676-3678.

22. Liu F, Liao D. Clinical efficacy of ginseng white centralizer granule in the treatment of cancer related anemia. J Luzhou Med Coll. 2015;38(3): 280-282.

23. Zhang X. Clinical efficacy of Chinese and western medicine in the treatment of neoplastic anemia. Sichuan Tradit Chin Med. 2007;25(5):54-55.

24. Xiang N, Cheng J, Shao G. Research progress on cancer-related anemia. J Basic Clin Oncol. 2013;26(2):159-162. 
25. Yin L, Xu L, Hu G. Advance in herb medicine and its bioactive compounts in antitumor's mechanism. Prog In Vet Med. 2006;27(1):39-43.

26. Gao M. Traditional Chinese medicine. Beijing, China: Traditional Chinese Medicine Press; 2007:460-467.

27. Sun Z, Shao J, Guo M. Research progress on pharmacological activity of active ingredient in Codonopsis pilosula. J Anhui Agricult Sci. 2015; 43(33):174-176.

28. Zhang Q, Gao W, Li S. Research progress on pharmacological activity of active ingredient in astragalus. China J Chin Mater Med. 2012;37(21): 3203-3207.
29. Li X, Zhang L, Wang X, Yang W, Jin Y, Lv G. [Advances in the study of the chemical components and pharmacological effects of Angelica]. J Chin Med Mater. 2013;36(6):1023-1028. Chinese.

30. Pan Y, Liu T, Liang W, Wei X, Li X, Huang H. Safety profile of traditional Chinese medicine use: an analysis based on 166 cases of adverse reactions/events reports associated with traditional Chinese medicines. Chin J Hosp Pharm. 2016;36(2):145-148.

\section{Publish your work in this journal}

Drug Design, Development and Therapy is an international, peerreviewed open-access journal that spans the spectrum of drug design and development through to clinical applications. Clinical outcomes, patient safety, and programs for the development and effective, safe, and sustained use of medicines are the features of the journal, which has also been accepted for indexing on PubMed Central. The manuscript management system is completely online and includes a very quick and fair peer-review system, which is all easy to use. Visit http://www.dovepress.com/testimonials.php to read real quotes from published authors.

Submit your manuscript here: http://www.dovepress.com/drug-design-development-and-therapy-journal 